\title{
Estudo Comparativo, Prospectivo, Randomizado, do Tratamento da Úlcera Venosa com Espuma de Polidocanol e Tratamento Cirúrgico, no Ambulatório de Doenças Venosas do H.C.F.M.U.S.P.
}

\author{
Campos WJR. ${ }^{1}$, Leão PP. ${ }^{1}$, \\ Silva ES. ${ }^{1}$, Casella I. ${ }^{1}$ \\ ${ }^{1}$ HCFMUSP - São Paulo - Brasil. \\ E-mail: camposwalter2@terra.com.br
}

Campos, W.J.R.; Leão, P.P.; Silva, E.S.; Casella, I. 2013. Estudo Comparativo, Prospectivo, Randomizado, do Tratamento da Úlcera Venosa com Espuma de Polidocanol e Tratamento Cirúrgico, no Ambulatório de Doenças Venosas do H.C.F.M.U.S.P, p.50. In: Bastos, Francisco Reis. Anais do V Simpósio Internacional de Flebologia [Blucher Medical Proceedings n.1 v.1]. São Paulo: Blucher, 2014

http://dx.doi.org/10.5151/medpro-flebo-SIF_28

\section{Objetivo}

Comparar a eficácia e segurança do tratamento escleroterápico por espuma de polidocanol versus a cirurgia de varizes em pacientes portadores de úlcera venosa, com enfoque primário na cicatrização ulcerosa, melhora da qualidade.

\section{Material e Método}

No período de 07/08/07 a 28/02/10, quarenta e nove pacientes (13 do sexo masculino e 36 do sexo feminino), que apresentavam 51 membros inferiores com insuficiência venosa primária, úlcera venosa em atividade (C6) e insuficiência de veia safena interna, foram acompanhados no ambulatório de doenças venosas do H.C.F.M.U.S.P. Os dois grupos foram submetidos a questionário de qualidade de vida (Aberdeen) e nota de avaliação clínica da classificação CEAP.Vinte e oito membros foram submetidos a tratamento cirúrgico convencional, com safenectomia, exerese de colaterais e ligadura de veias perfurantes.Vinte e três membros foram submetidos a escleroterapia da veia safena insuficiente com espuma de polidocanol a 3\% (1 a 3 sessões), pela técnica descrita por Tessari. Os dois grupos foram reavaliados após o periodo de 4 a 27 meses e submetidos a novo questionário. Foi realizada análise estatística dos dados obtidos com o nota da classificação CEAP, questionário de qualidade de vida Aberdeen, tempo de cicatrização da ferida, recidiva da ferida e complicações dos procedimentos.

\section{Resultados}

O tempo de seguimento médio dos pacientes foi de $502 \pm 220$ dias. Houve cicatrização da úlcera em 28 pacientes (100\%) do grupo cirúrgico e 19 pacientes $(91,3 \%)$ do grupo de escleroterapia, sem diferença estatística entre os tratamentos ( $\mathrm{P}=.19$ - Teste de Fisher). No entanto os pacientes submetidos à cirurgia de varizes apresentaram um tempo médio de ci- 


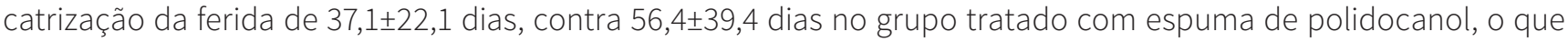
representa uma diferença significativa ( $P=0.008$ - Teste de Log Rank). A incidência de complicações foi de 14,2\% no grupo de cirurgia e 13,0\% no de escleroterapia ( $\mathrm{P}=1.0$, teste de Fisher). Houve quatro casos de recidiva da úlcera no grupo de escleroterapia e dois entre os pacientes cirúrgicos ( $\mathrm{P}=0.39$, teste de Fisher). Ambos os tratamentos proporcionaram melhora clínica significativa aos pacientes. No grupo cirúrgico, o índice de severidade clinica venosa médio reduziu-se de 12,5 para 3,39 e o índice de incapacitação por doença venosa médio reduziu-se de 2,14 para 1,18 ( $\mathrm{P}<0.001$ para ambos, Teste de Wilcoxon). De forma semelhante, no grupo tratado por escleroterapia o índice de severidade clinica venosa médio reduziu-se de 12,26 para 4,26 e o índice de incapacitação por doença venosa médio reduziu-se de 2,00 para 1,09 ( $\mathrm{P}<0.001$ para ambos, Teste de Wilcoxon). Os índices de prejuízo da qualidade de vida, inicialmente altos para ambos os grupos também sofreram importante redução. Os valores pré-tratamento foram de 40,31 e 37,72 para os grupos de cirurgia e de escleroterapia, respectivamente. Ao término do seguimento, estes valores reduziram-se para 12,30 e 15,95 nos respectivos grupos ( $\mathrm{P}<0,001$ para ambos, Teste de Wilcoxon). Quando os resultados clínicos e de qualidade de vida são comparados entre os dois métodos de tratamento, não há diferenças nos resultados finais dos índices de severidade clinica venosa, de incapacitação por doença venosa e de prejuízo da qualidade de vida ( $P=0.58,0.66$ e 0.45 , respectivamente, teste $U$ de Mann-Whitney).

\section{Conclusões}

A escleroterapia não se mostrou inferior ao tratamento cirúrgico, podendo se uma alternativa terapêutica para pacientes com risco cirúrgico alto, ou políticas de saúde publica para tratamento ambulatorial de insuficiência venosa avançada com úlcera em atividade.

Palavras-chave: Tratamento de varizes, escleroterapia com espuma, úlcera de estase 